Research Paper

\title{
Antrodia cinnamomea Galactomannan Elicits Immuno- stimulatory Activity Through Toll-like Receptor 4
}

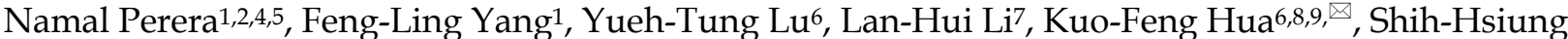
$\mathrm{Wu}^{1,2,3, \mathbb{}}$

1. Institute of Biological Chemistry, Academia Sinica, Taipei, Taiwan

2. Chemical Biology and Molecular Biophysics Program, Taiwan International Graduate Program, Academia Sinica, Taipei, Taiwan

3. Department of Chemistry and Institute of Biochemical Sciences, National Taiwan University, Taiwan

4. Department of Chemistry, National Tsing-Hua University, Hsinchu, Taiwan

5. Faculty of Applied Sciences, Sabaragamuwa University of Sri Lanka, Sri Lanka

6. Department of Biotechnology and Animal Science, National Ilan University, Ilan, Taiwan

7. Department of Laboratory Medicine, Linsen, Chinese Medicine and Kunming Branch, Taipei City Hospital, Taipei, Taiwan

8. Department of Pathology, Tri-Service General Hospital, National Defense Medical Center, Taipei, Taiwan

9. Department of Medical Research, China Medical University Hospital, Taichung, Taiwan

Namal Perera, Feng-Ling Yang: equal contribution

$\triangle$ Corresponding authors: E-mail: shwu@gate.sinica.edu.tw; Tel.: +886-(02) 2785-5696 Fax: +886-(02) 2653-9142; E-mail: kfhua@niu.edu.tw; Tel.: +886-(03) 931-7626 Fax: +886-(03) 931-1526

(c) Ivyspring International Publisher. This is an open access article distributed under the terms of the Creative Commons Attribution (CC BY-NC) license (https://creativecommons.org/licenses/by-nc/4.0/). See http://ivyspring.com/terms for full terms and conditions.

Received: 2017.12.26; Accepted: 2018.06.29; Published: 2018.07.27

\begin{abstract}
Antrodia cinnamomea ( $A$. cinnamomea) is a medicinal fungus used in traditional Chinese medicine to treat different kinds of ailments, including liver diseases, abdominal pain, drug intoxication, diarrhea, itchy skin, hypertension, and cancer. Polysaccharides have been identified as one of the major pharmacologically active ingredients present in $A$. cinnamomea. The present study aims to investigate the immunoenhancing activity of galactomannan isolated from $A$. cinnamomea. The cold water-soluble polysaccharide (galactomannan-repeated; $M W>70 \mathrm{kDa}$; named $A C P$ ) of $A$. cinnamomea was isolated, and immunostimulatory properties were studied through different immune cell models including mouse macrophages and human dendritic cells. Through Toll-like receptor 4, ACP stimulated tumor necrosis factor- $\alpha$ (TNF- $\alpha$ ) and interleukin-6 (IL-6) in J774A.1 mouse macrophages, mouse peritoneal macrophages and human dendritic cells. It was further identified that ACP elicited its immunostimulatory activity through protein kinase C- $\alpha$ (PKC- $\alpha$ ) and mitogen activated protein kinases (MAPK) phosphorylation. Furthermore, ACP exerted the endotoxin tolerance-like effect through NF- $\kappa B$ inhibition. These findings demonstrate the potential of $A$. cinnamomea galactomannan as an immunostimulator or an adjuvant in immunotherapy and vaccination.
\end{abstract}

Key words: Antrodia cinnamomea, galactomannan, macrophages, dendritic cells, immunostimulation

\section{Introduction}

Medicinal mushrooms have been used as integral ingredients of dietary supplements in the last few decades. It is estimated that $80-85 \%$ of all medicinal mushrooms products are derived from fruiting bodies, which can either be artificially cultured or collected from nature [1]. The potent therapeutic activities of medicinal mushrooms, including chemopreventive and immunomodulatory activities, have garnered much attention [2-4].
Currently, important medicinal mushrooms used worldwide as dietary supplements, including Antrodia cinnamomea, Cordyceps sinensis, Ganoderma lucidum, Phellinus igniarius, Polystictus versicolori, Agaricus blazei Murill, Coriolus versicolor, and Poria cocos [5,6]. Molecules containing polysaccharides, such as the proteoglycans of Ganoderma lucidum [7], $\beta$-1,3-glucans and $\beta$-1,6-glucans of Agaricus blazei Murill [8,9], and protein-bound beta-glucan 
polysaccharides (PSKs, known as Krestin in Japan) have known antitumor and immunological activities [10]. More specifically, the polysaccharides of Ganoderma lucidum have immunomodulatory, anti-angiogenic and cytotoxic effects [11], potential hypoglycemic and hypolipidemic activities [12], and anti-obesity and microbiota-modulating effects [13]. Lentinan of Lentinus edodes has antitumor, anti-virus, anti-bacteria, and anti-parasitic infections [14,15].

Antrodia cinnamomea, in the phylum Basidiomycota, grows as a parasitic fungus on Cinnamomum kanehirai and is a mushroom unique to Taiwan [16,17]. Historically, it has been used by Chinese ethnomedical practitioners to treat different kinds of ailments, including liver diseases, abdominal pain, drug intoxication, diarrhea, itchy skin, hypertension, and cancer [18-20]. Currently, it is considered a potent nutraceutical with very high economic value and demand. Based on its medicinal efficacy, the total market value of A. cinnamomea products, including raw fruiting bodies and health foods, is estimated to be more than US\$100 million per year [16]. Hundreds of A. cinnamomea small molecules with different biological activities have been identified as active constituents [2]. The most important pharmacologically active constituents of $A$. cinnamomea are triterpenoids, steroids, benzoquinone derivatives, and polysaccharides [14]. Some crude polysaccharide fractions also have certain biological activities, including immunomodulatory, antitumor, antioxidant, and antiangiogenic activities [21-28]. The well-established chemical structures of $A$. cinnamomea polysaccharides were represented as fucosylated mannogalactan (PS) (400 kDa, major in galactose, minor in fucose and mannose, galactose: fucose: mannose in the ratio of 13: 4: 2) which showed antiangiogenic activity [27, 28] and galactomannan (ACP) (100 kDa, 75\% mannose and 25\% galactose) [29], with phagocytosis-enhancing activity. In the present study we investigated the immunostimulatory features of $\mathrm{ACP}$, which is composed of octasaccharide repeating unit $\{\rightarrow 6)$-D-Man $p$-( $(\mathrm{a} 1 \rightarrow 2)$-D-Man $p$ - $(\alpha 1 \rightarrow 2)$ [D-Manp-(a1 $\rightarrow$ 3)-D-Manp-(a1 $\rightarrow$ 2)-D-Manp-(a1 $\rightarrow$ 6)-D-Galp-(a1 $\rightarrow$ 6)]-D-Manp-(a1 $\rightarrow$ 6)-D-Galp-(a1 $\rightarrow$ [ [Figure 1].

The immune system is critical in maintaining human health in the face of infectious organisms and tumor cells [30]. Parts of this system, TNF- $\alpha$ and IL-6, are important pro-inflammatory cytokines produced mainly by activated macrophages, and they mediate multiple biological effects [31-33]. Thus, natural substances that can stimulate TNF- $\alpha /$ IL- 6 have the potential to be adjuvants in immunotherapy and vaccination. Complex carbohydrates have attracted growing scientific interest over the past few decades for their immunoenhancing properties. However, their contribution as clinical adjuvants is still limited because of the structural complexity and the lack of studies on the structure-activity relationship and the underlying mechanisms of the biological activity of the individual polysaccharide components. In this study, we report the in vitro immunostimulatory potential of ACP on J774A.1 murine macrophage and human dendritic cell models as well as some signaling pathways involved in its mechanism of action, which deepens the current understanding of the immunomodulatory potential of this precious natural resource.

\section{Materials and Methods}

\section{Materials}

The procedures for the isolation of cold-water soluble polysaccharide and the structure elucidation of ACP were described in our recent publication [29].

LPS (from Escherichia coli 0111: B4), polymyxin B, peptidoglycan (PGN, from Staphylococcus aureus), mouse antibodies for mouse phospho-ERK1/2, phospho-JNK1/2, phospho-p38, and actin were purchased from Sigma-Aldrich (St. Louis, MO). Antibodies for phospho-PKC- $\alpha / \delta$, IL-1 $\beta$, COX-2, and secondary antibodies were obtained from Santa Cruz Biotechnology (Santa Cruz, CA). IL-1 $\beta$, IL-6, TNF- $\alpha$, and MCP-1 ELISA kits were purchased from R\&D Systems (Minneapolis, MN).

\section{Cell culture}

Mouse J774A.1 macrophages were obtained from the American Type Culture Collection (ATCC, Manassas, VA). Cells were propagated in RPMI 1640 medium supplemented with $10 \%$ heat-inactivated fetal bovine serum (FBS, HyClone, Logan, UT) and 2 $\mathrm{mM}$ L-glutamine (Invitrogen Life Technologies, Carlsbad, CA) and then cultured at $37^{\circ} \mathrm{C}$ in a $5 \% \mathrm{CO}_{2}$ incubator. All plasmids were purchased from Santa Cruz Biotechnology (Santa Cruz, CA): ERK1 shRNA plasmid (sh-ERK1, sc-29308-SH), JNK1 shRNA plasmid (sh-JNK1, sc-29381-SH), p38a shRNA

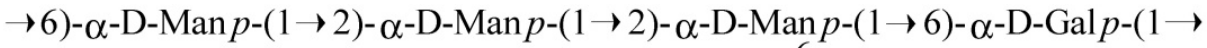

$$
\begin{aligned}
& \alpha \text {-D-Man } p \text { - }(1 \rightarrow 3)-\alpha \text {-D-Man } p-(1 \rightarrow 2)-\alpha \text {-D-Man } p \text { - }(1 \rightarrow 6)-\alpha \text {-D-Gal } p \text { - }(1
\end{aligned}
$$


plasmid (sh-p38a, sc-29434-SH), p38 $\beta$ shRNA plasmid (sh-p38 $\beta$, sc-39117-SH), TLR2 shRNA plasmid (sh-TLR2, sc-40257-SH) and TLR4 shRNA plasmid (sh-TLR4, sc-40261-SH). NF-kB reporter cells, (J-Blue cells), were generated by stable transfection of J774A.1 macrophages with a secreted embryonic alkaline phosphatase (SEAP) reporter construct (pNiFty2-SEAP, Catalog number: pnifty2-seap, purchased from Invitrogen, Carlsbad, CA, USA) induced by NF-kB.

\section{Isolation of mouse peritoneal macrophages}

Male C57BL mouse was intraperitoneally injected with $2 \mathrm{~mL}$ of thioglycollate for 3 days. Peritoneal exudate cells $\left(1 \times 10^{6} / \mathrm{mL}\right)$ isolated from the peritoneal fluids were cultured in 6-well plates for $2 \mathrm{~h}$, and the non-adherent cells were removed through gentle washing 3 times with PBS. The adherent macrophages were stimulated as indicated.

\section{Generation of Human Monocyte-derived Dendritic Cells}

The detailed protocol for generating monocytes-derived dendritic cells (DC) was described in our previous study [34]. In brief, whole blood sample $(250 \mathrm{~mL})$ was obtained from one healthy volunteer. PBMCs were separated from the whole blood through Ficoll-Hypaque density gradient centrifugation, and then monocytes were isolated through the plastic adherence method. Immature dendritic cells were generated from the culture of the isolated monocytes $\left(1 \times 10^{6} / \mathrm{mL}\right)$, which was treated for 6 days in 6-well plates with RPMI 1640 medium supplemented with $500 \mathrm{U} / \mathrm{mL}$ recombinant human GM-CSF and 1,000 U/mL recombinant human IL-4 (PeproTech, Rocky Hill, NJ). On days 2 and 4, half the medium was replaced with fresh medium containing recombinant human GM-CSF and recombinant human IL-4.

\section{ELISA assay}

Cells $\left(2 \times 10^{5} /\right.$ well $)$ were seeded in 24-well plates and treated as indicated. Secretion of TNF- $\alpha$, IL-6, and IL-1 $\beta$ was measured by ELISA according to the manufacturer's protocol (R\&D systems Minneapolis).

\section{Western blot assay}

After treatment, the cells were collected and lysed at $4{ }^{\circ} \mathrm{C}$ in lysis buffer containing protease inhibitor cocktail (Sigma-Aldrich, St. Louis, MO). The whole cell lysate was centrifuged at $4^{\circ} \mathrm{C}$, and the supernatant was separated by SDS-PAGE and electrotransferred to a PVDF membrane (Millipore,
Billerica, MA). The membranes were incubated at $4{ }^{\circ} \mathrm{C}$ overnight in blocking buffer, and they were further incubated for $2 \mathrm{~h}$ at room temperature with specific primary antibody in blocking buffer. After three washes in PBS with $0.1 \%$ Tween 20, the membrane was incubated for $1 \mathrm{~h}$ at room temperature with HRP-conjugated secondary antibody in blocking buffer and developed through an enhanced chemiluminescence Western blot detection system (Millipore, Billerica, MA).

\section{NF-KB reporter assay}

J-Blue cells, J774A.1 macrophages stably expressing the gene for secreted embryonic alkaline phosphatase induced by NF- $\mathrm{kB}$, were seeded in a 24-well plate at a density of $2 \times 10^{5}$ cells in $0.5 \mathrm{~mL}$ medium and grown overnight in a $5 \% \mathrm{CO}_{2}$ incubator at $37{ }^{\circ} \mathrm{C}$. Cells were then treated with negative control, positive control, or ACP and incubated for another 24 $\mathrm{h}$. The medium $(20 \mu \mathrm{L})$ from treated J-Blue cells was mixed with $200 \mu \mathrm{L}$ of QUANTI-Blue ${ }^{\mathrm{TM}}$ medium (Invitrogen, Carlsbad, CA) in 96-well plates and incubated at $37^{\circ} \mathrm{C}$ for $15 \mathrm{~min}$. The secreted embryonic alkaline phosphatase activity was assessed with a microplate absorbance reader measuring the optical density at $655 \mathrm{~nm}$.

\section{Statistical Analysis}

All values are given as mean \pm standard deviations (SDs). Data analysis involved one-way analysis of variance (ANOVA) with subsequent Scheffe's test.

\section{Results and Discussion}

\section{ACP induces TNF- $\alpha$ and IL-6 secretion in mouse macrophages and human monocyte-derived dendritic cells}

TNF- $\alpha$ and IL- 6 are important pro-inflammatory cytokines produced mainly by activated macrophages and dendritic cells; they mediate multiple biological effects, including the activation of immune responses [31-33]. To detect the effect of ACP on macrophage activation, we quantified TNF- $\alpha$ and IL- 6 levels in the conditioned medium of ACP-stimulated murine J774A.1 macrophages through ELISA. As shown in Figure $2 \mathrm{~A}, 0.25,0.45$, and $1.3 \mathrm{ng} / \mathrm{mL}$ of TNF- $\alpha$ were detected in the conditioned medium of 10,30 , and 100 $\mu \mathrm{g} / \mathrm{ml}$ ACP-treated J774A.1 macrophages, respectively. Relatively, the concentration of lipopolysaccharide $(1 \mu \mathrm{g} / \mathrm{mL}$ LPS from $E$. coli) induced TNF- $\alpha$ level was $33 \mathrm{ng} / \mathrm{mL}$. 
(A)

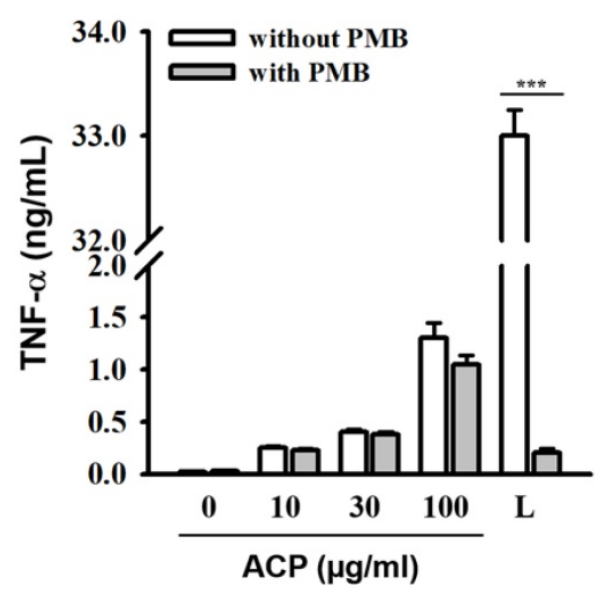

(B)

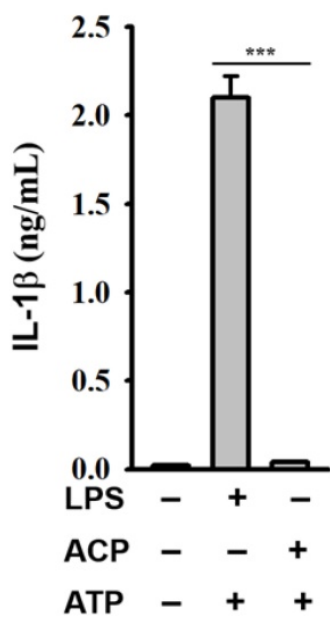

(C)

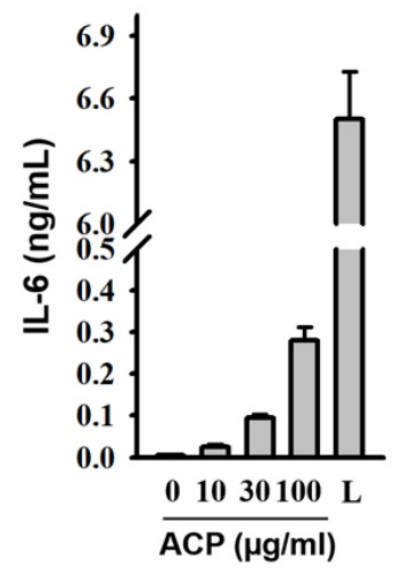

(D)

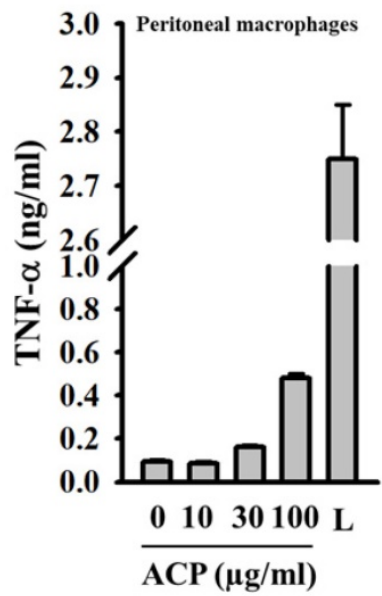

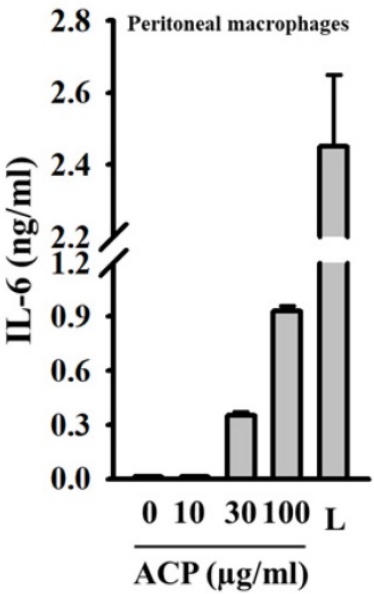

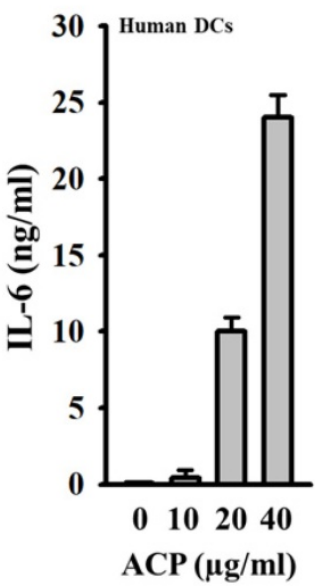

Figure 2. ACP induces cytokine expression in macrophages and dendritic cells. (A) J774A.1 macrophages were incubated for 30 min with or without polymyxin $B$ (PMB) $(10 \mu \mathrm{g} / \mathrm{mL})$ and then for $24 \mathrm{~h}$ with or without ACP or LPS $(1 \mu \mathrm{g} / \mathrm{mL})$. The levels of TNF- $\alpha$ in the culture medium were measured by ELISA. (B) J774A. 1 macrophages were incubated for $5.5 \mathrm{~h}$ with or without ACP $(100 \mu \mathrm{g} / \mathrm{mL})$ or LPS $(1 \mu \mathrm{g} / \mathrm{mL})$ and then for $30 \mathrm{~min}$ with or without ATP $(5 \mathrm{mM})$. The levels of IL-1 $\beta$ in the culture medium were measured by ELISA. (C) ]774A.1 macrophages were incubated for $24 \mathrm{~h}$ with or without ACP or LPS $(1 \mu \mathrm{g} / \mathrm{mL}$ ). The levels of IL- 6 in the culture medium were measured by ELISA. (D) Mouse peritoneal macrophages were incubated for $24 \mathrm{~h}$ with or without ACP or LPS $(1 \mu \mathrm{g} / \mathrm{mL}$ ). The levels of TNF- $\alpha$ and IL-6 in the culture medium were measured by ELISA. (E) Human monocyte-derived dendritic cells were incubated for $24 \mathrm{~h}$ with or without ACP or LPS $(1 \mu \mathrm{g} / \mathrm{mL})$. The levels of TNF- $\alpha$ and IL-6 in the culture medium were measured by ELISA. The data are expressed as the means \pm SD of three separate experiments. $* * *$ indicates a significant difference at the level of $p<0.001$. L: LPS

Lipopolysaccharide (LPS), a potent macrophage stimulator, is often presented as a contaminant in natural polysaccharides. Therefore, it is extremely important to avoid false positive responses caused by such contaminations. The effect polymyxin B (PMB), an LPS-sequestering agent, on ACP- and LPS-induced TNF- $\alpha$ levels in J774A.1 macrophages was tested to rule out the possibility of endotoxin contamination in $\mathrm{ACP}$. As shown in Figure 2A, ACP-induced TNF- $\alpha$ secretion was not reduced by $\mathrm{PMB}$, but $\mathrm{PMB}$ significantly inhibited the LPS-induced TNF- $\alpha$ secretion. In addition, NLRP3 inflammasome, a protein complex composed of NLRP3, ASC and caspase-1, which regulates IL-1 $\beta$ secretion, was activated by LPS in the presence of ATP. However, $\mathrm{ACP}$ was not able to activate the NLRP3 inflammasome (Figure 2B). These results clearly demonstrated that ACP was not contaminated with LPS. ACP also induced IL-6 secretion in a dose-dependent fashion in J774A.1 macrophages (Figure 2C). The cytokine induction ability of ACP in macrophages was further confirmed through the measurement of TNF- $\alpha$ and IL- 6 secretion in mouse primary peritoneal macrophages upon ACP treatment. We observed that ACP induced TNF- $\alpha$ and IL-6 secretion in mouse primary peritoneal macrophages in a concentration-dependent manner (Figure 2D). Furthermore, there was a 
dose-dependent increase of TNF- $\alpha$ and IL-6 levels in the ACP-treated human primary monocyte-derived dendritic cells (Figure 2E). These results indicate that

(A)
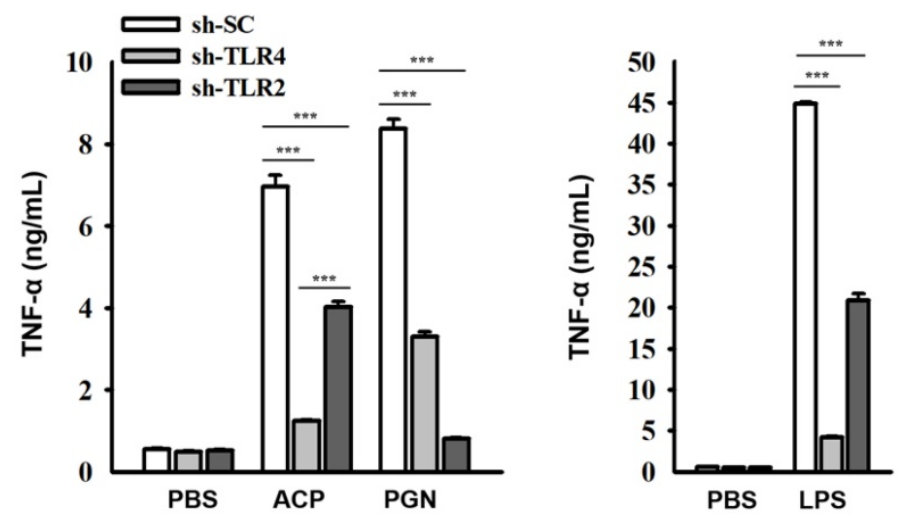

(B)
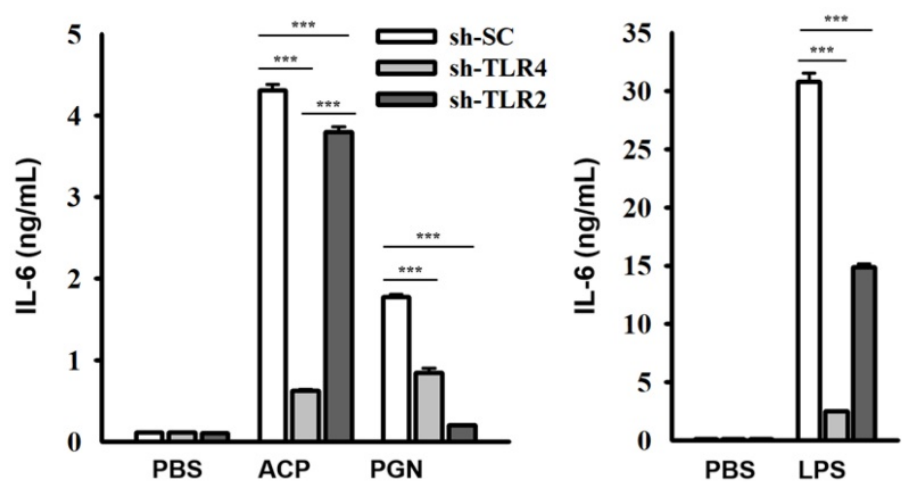

(C)
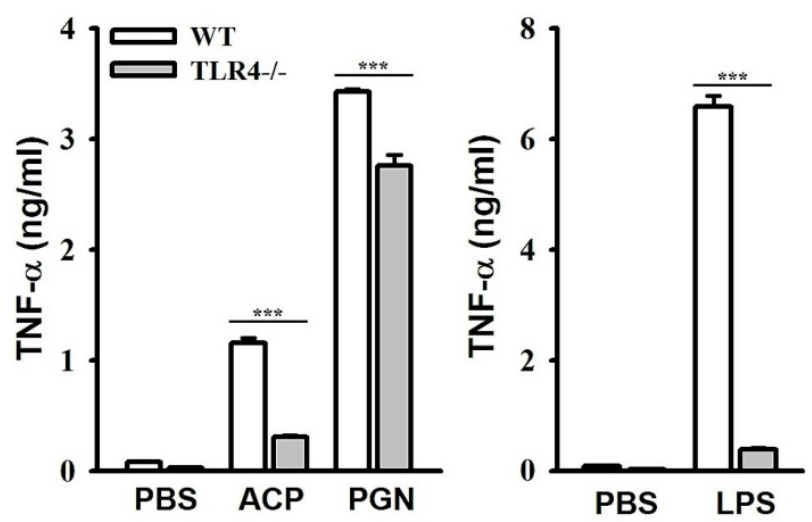

Figure 3. ACP induces cytokine expression through TLR4. (A, B) J774A.1 macrophages stably transfected with a control shRNA plasmid (sh-SC), a TLR4 shRNA plasmid (sh-TLR4), and a TLR2 shRNA plasmid (sh-TLR2) were incubated for $24 \mathrm{~h}$ with or without ACP $(100 \mu \mathrm{g} / \mathrm{mL})$, PGN $(10 \mu \mathrm{g} / \mathrm{mL})$ or LPS $(1 \mu \mathrm{g} / \mathrm{mL})$. The levels of TNF- $\alpha(\mathbf{A})$ and IL-6 (B) in the culture medium were measured by ELISA. (C, D) Mouse peritoneal macrophages isolated from wild-type (WT) and TLR4 knockout (TLR4-/-) mice were incubated for $24 \mathrm{~h}$ with or without ACP $(100 \mu \mathrm{g} / \mathrm{mL})$, PGN $(10 \mu \mathrm{g} / \mathrm{mL})$ or LPS $(1 \mu \mathrm{g} / \mathrm{mL})$. The levels of TNF- $\alpha(C)$ and IL- 6 (D) in the culture medium were measured by ELISA. (E) J774A.1 macrophages were incubated for $30 \mathrm{~min}$ with or without ACP $(100 \mu \mathrm{g} / \mathrm{mL})$ and then for $24 \mathrm{~h}$ with or without LPS $(1 \mu \mathrm{g} / \mathrm{mL})$. The levels of TNF- $\alpha$ in the culture medium were measured by ELISA. The data are expressed as the means \pm SD of three separate experiments. $* * *$ indicates a significant difference at the level of $p<0.001$
$\mathrm{ACP}$ is able to activate an immune response to induce cytokine secretion in both macrophages and dendritic cells.

A previous study revealed the strong induction effect of the high molecular weight $(>$ $100 \mathrm{kDa})$ polysaccharide fraction of $A$. cinnamomea has on dendritic cells in secreting TNF- $\alpha$, IL-6, and IL-12 [23]. In a similar vein, the polysaccharides of $A$. cinnamomea were reported to have various other biological activities related to immunity modulation, including anti-HepG2 $[17,35,36]$, anti-tumors [23], IL-6, TNF- $\alpha$, IL-10, and monocyte chemotactic protein-1,_all of which decrease the inflammatory mediator expression at the location of injury and in circulation [37] and suppress angiogenesis [26,27,38]. The high molecular weight (MW > $100 \mathrm{kDa}$ ) polysaccharide fraction was the most effective in inhibiting vascular endothelial growth factor, it increased the levels of IL-12 and IFN- $\gamma$ secretion of mononuclear cells [39]. The immunomodulatory effect of the polysaccharides from A. cinnamomea mycelia induced Th1-type cytokines (IFN- $\gamma$, TNF- $\alpha$ ) that are crucial for both cell-mediated and humoral immunity [40]. Even though aforementioned polysaccharides from $A$. cinnamomea have shown immunostimulatory effects, certain Antrodia polysaccharides have also shown antiinflammatory activities. For example, Antrodan, a $442 \mathrm{kD}$ glycoprotein purified from $A$. cinnamomea that contains a particularly high content of uronic acid, is reported to have a potent suppressive effect on the lipopolysaccharide-induced inflammatory responses in the Raw 264.7 cell line [38], anti-metastatic effects in lung carcinoma cells [25], and hepatoprotective activity [41].

\section{ACP induces cytokine expression mainly through TLR4}

The roles of TLRs including TLR2 and TLR4, in polysaccharides-mediated cytokine induction have been elucidated [7, 42-47]; however, the roles of TLRs playing in recognizing the immunological polysaccharides of A. cinnamomea were less studied. We observed that the secretion of ACP-induced TNF- $\alpha$ (Figure 3A) and IL-6 (Figure 3B) was significantly reduced in J774A.1 macrophages stably transfected with shRNA plasmids targeting TLR4 (sh-TLR4), compared with that in the cells stably transfected with a control shRNA plasmid encoding a scrambled shRNA sequence (sh-SC). These results indicated that TLR4 is one of the putative receptors for ACP. Notably, ACP- and 
LPS-induced TNF-a and IL-6 secretions were also reduced in sh-TLR2 cells. Some mannose-containing glycoconjugates/polysaccharides have been reported to be recognized by TLR-2 and TLR-4 [48,49]. During the isolation procedure of ACP, the sample was heat-denatured and treated with protease $\mathrm{K}$ to digest the protein part in the sample completely that the contamination of the fungal peptidoglycan would be prevented. We believed that the reduced secretions of TNF- $\alpha$ and IL-6 in ACP-treated sh-TLR2 cells were not due to peptidoglycan contamination, but TLR2 may partially contribute to the cytokine induction activity of ACP. The more detailed investigation are required, including defined oligosaccharides as ligands for TLR2 and TLR4 activation and binding.

To confirm the role of TLR4 played in ACP-mediated cytokine secretion, we compared the cytokine induction activity of ACP in primary peritoneal macrophages isolated from wild-type (WT) mice with those from TLR4-deficient (TLR4-/-) mice. The secretion of ACP- and LPS-induced TNF- $\alpha$ (Figure 3C) and IL-6 (Figure 3D) in peritoneal macrophages from TLR4-/- mice was significantly lower than that in peritoneal macrophages from WT mice, whereas the secretion of peptidoglycan, a TLR2 ligand-induced TNF- $\alpha$ and IL- 6 was not impaired in peritoneal macrophages from TLR4-/- mice. These results indicated that TLR4 functions as a major putative receptor for ACP. In addition, ACP pretreatment did not significantly reduce the secretion of LPS-induced TNF- $\alpha$, and that indicated $\mathrm{ACP}^{\prime}$ s inability to significantly compete with LPS in binding to TLR4 (Figure 3E). These results indicated that both ACP and LPS could bind to TLR4 and might have different TLR4 interaction sites respectively. Recent studies on the adjuvant effects, hot water-extracted $A$. cinnamomea high-molecule-weight polysaccharides (greater than $100 \mathrm{kDa}$ ) working on dendritic cell activation and maturation [23] revealed to the TLR2/TLR4 and NF-кB/MAPK signaling pathways, induction of $\mathrm{T}$ cell activation, and Th1 differentiation. A lot of TLR4-related polysaccharide ligands have been identified, with varying molecular weights and different monosaccharide compositions. Additionally, homoglycans, which contain glucan, galactan, and mannan, are well- known TLR4 ligands [50]. Glucose, mannose, galactose, fucose, and sialic acid have been identified as the possible key "pharmacophore" of TLR4/MD-2 polysaccharide ligands, and they may participate in enhancing ligand interaction with TLR4/MD-2 [50]. Furthermore, $\alpha-(1-3), \alpha-(1-4), \beta-(1-3)$, and $\beta-(1-4)$ glycosidic linkages containing polysaccharides are more frequently reported as the TLR4 ligands [50].

\section{ACP induces cytokine secretion through MAPK}

Activation of TLR4 results in the activation of downstream mitogen-activated protein kinases (MAPK, including ERK1/2, JNK1/2, and p38) and leads to the production of proinflammatory mediators [47]. To examine whether the secretion of ACP-induced TNF- $\alpha$ and IL-6 was associated with MAPK signaling pathways, we measured the phosphorylation levels of ERK1/2, JNK1/2, and p38 in ACP-activated J774A.1 macrophages through Western blot analysis, and the results revealed that phosphorylation levels of ERK1/2, JNK1/2, and p38 were increased by ACP compared with those in control cells (Figure 4A). The effect ACP on TNF- $\alpha$ and IL-6 secretion in J774A.1 macrophages, which are stably transfected with shRNA plasmids targeting

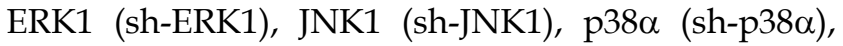
and p38 $\beta$ (sh-p38 $\beta$ ), was investigated to elucidate the role MAPK plays in the regulation of cytokine secretion in ACP-activated macrophages. Significantly lower TNF- $\alpha$ (Figure 4B) and IL-6 (Figure 4C) secretion was observed in ACP-treated sh-ERK1, sh-JNK1, and sh-p38 $\alpha$ cells compared with that in cells stably transfected with a control shRNA plasmid encoding a scrambled shRNA sequence (sh-SC). However, no significant difference was detected between sh-p38 $\beta$ and sh-SC cells in ACP-induced TNF- $\alpha$ and IL-6 secretion (Figures 4B and $4 \mathrm{C}$ ), and that indicated the mediation of ERK1, JNK1 and p38 $\alpha$ in ACP-induced cytokine secretion.

\section{ACP induces cytokine secretion through PKC}

Protein kinase $C$ family proteins have been extensively studied for their mediation in immunomodulatory signal transduction and immune cell regulation processes. The potential of polysaccharide-based prebiotics in strengthening the intestinal epithelial barrier through PKC- $\delta$ signaling has been recently reported [51]. Further activation of PKC- $\alpha$ and $\delta$ in macrophages by fungal polysaccharides (Ganoderma lucidum) [7,42], exopolysaccharides from algae (Chlorella pyrenoidosa) [44], and capsular polysaccharides from bacteria (Klebsiella pneumoniae) [45] has also been reported. Therefore, in our study, we examined the possible involvement of protein kinase $\mathrm{C}$ (PKC) in ACP-induced TNF-a secretion. As revealed through the Western blot analysis, phosphorylation levels of PKC- $\alpha$ and PKC- $\delta$ were increased in ACP-activated J774A.1 macrophages compared with those in the ACP untreated cells (Figure 5A). The roles of PKC- $\alpha$ and PKC- $\delta$ playing in the regulation of TNF- $\alpha$ secretion in ACP-activated macrophages were 
(A)

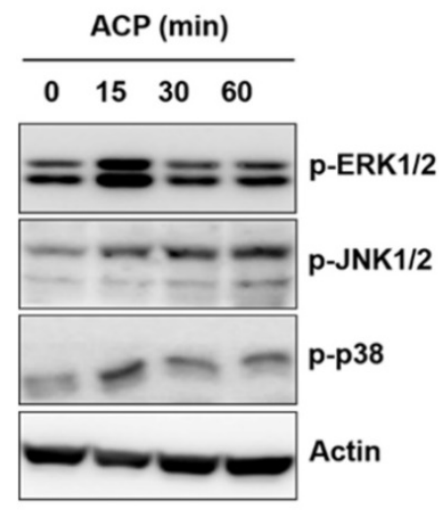

(B)

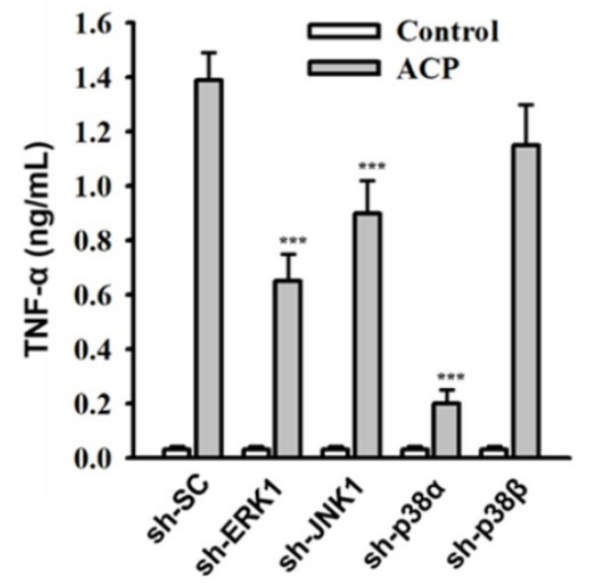

(C)

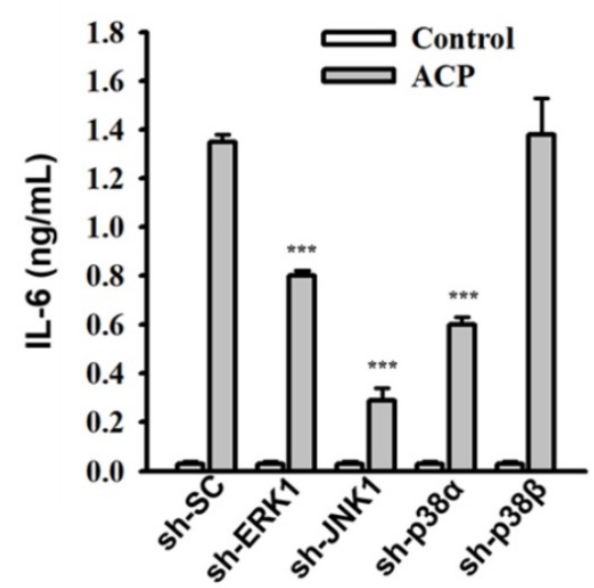

Figure 4. ACP induces cytokine expression through MAPK. (A) J774A.1 macrophages were incubated for $0-60 \mathrm{~min}$ with or without $\mathrm{ACP}$ ( $100 \mu \mathrm{g} / \mathrm{mL}$ ). The phosphorylation levels of ERK 1/2, JNK1/2 and p38 were assayed by Western blot. (B, C) J774A.1 macrophages stably transfected with a control shRNA plasmid (sh-SC), a ERK1 shRNA plasmid (sh-ERK1), a JNK1 shRNA plasmid (sh-TLR2), a p38 $\alpha$ shRNA plasmid (sh-p38 $\alpha$ ), and a p38 $\beta$ shRNA plasmid (sh-p38 $\beta$ ) were incubated for 24 h with or without ACP $(100 \mu \mathrm{g} / \mathrm{mL})$. The levels of TNF- $\alpha$ (B) and IL-6 (C) in the culture medium were measured by ELISA. The Western blot results are representative of those obtained in three different experiments. The ELISA data are expressed as the means \pm SD of three separate experiments. *** indicates a significant difference at the level of $p<0.001$.

elucidated in J774A.1 macrophages, which are stably transfected with shRNA plasmids targeting PKC- $\alpha$ (sh-PKC- $\alpha$ ) and PKC- $\delta$ (sh-PKC- $\delta$ ). We found that TNF- $\alpha$ secretion in ACP-activated sh-PKC- $\alpha$ cells was significantly lower than that in the cells stably transfected with a control shRNA plasmid encoding a scrambled shRNA sequence (sh-SC) (Figure 5B). In contrast, there was a significantly higher amount of TNF-a detected in ACP-treated sh-PKC- $\delta$ cells than that in the control sh-SC cells (Figure 5B). Additionally, COX-2 expression was also upregulated in ACP treated sh-SC cells and PKC- $\delta$ cells, but it was down-regulated in sh-PKC- $\alpha$ cells (Figure 5C). These results indicate that $\mathrm{ACP}$ induces $\mathrm{TNF}-\alpha$ secretion and COX-2 expression through PKC- $\alpha$. However, PKC- $\delta$ negatively regulates the ACP-induced TNF- $\alpha$ secretion.

\section{ACP induces endotoxin tolerance}

Primary exposure of cells to LPS leads to a reduced responsiveness to a second LPS challenge, a phenomenon known as endotoxin tolerance. Endotoxin tolerance is characterized as a global down-regulation of inflammatory gene expression [52], and it augments the bacterial clearance and improves survival rate of mice with sepsis [53]. Although ACP induces an increase in TNF- $\alpha$ and IL-6 secretion in macrophages, pre-incubation of J774A.1 macrophages with ACP for $24 \mathrm{~h}$ produced an endotoxin tolerance-like phenomenon, a markedly attenuated response to LPS stimulation with decreased TNF- $\alpha$ and IL-6 secretion (Figure 6A). The endotoxin tolerance-like phenomenon induced by $\mathrm{ACP}$ was also confirmed in mouse primary peritoneal macrophages (Figure 6B). The endotoxin tolerance- 
(A)

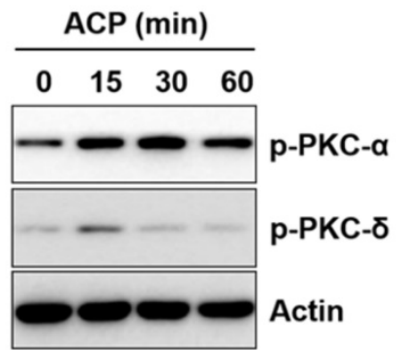

(C)

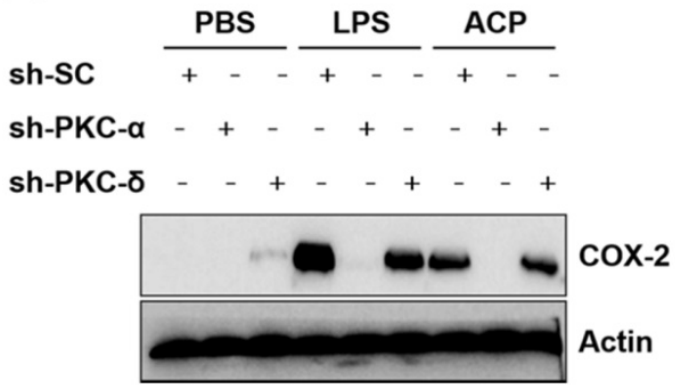

(B)

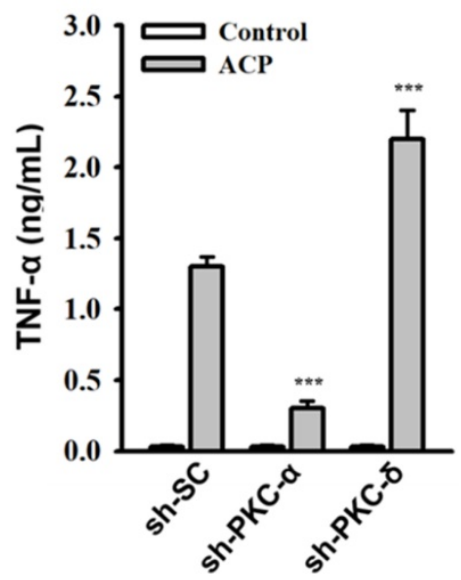

Figure 5. ACP induces cytokine expression through PKC- $\alpha$. (A) J774A.1 macrophages were incubated for $0-60 \mathrm{~min}$ with or without $\mathrm{ACP}$ (100 $\mu \mathrm{gg} / \mathrm{mL}$ ). The phosphorylation levels of PKC- $\alpha$ and PKC- $\delta$ were assayed by Western blot. (B) J774A.1 macrophages stably transfected with a control shRNA plasmid (sh-SC), a PKC- $\alpha$ shRNA plasmid (sh-PKC- $\alpha$ ), and a PKC- $\delta$ shRNA plasmid (sh-PKC- $\delta$ ) were incubated for $24 \mathrm{~h}$ with or without ACP (100 $\mu \mathrm{g} / \mathrm{mL})$. The levels of TNF- $\alpha$ in the culture medium were measured by ELISA. (C) sh-SC, sh-PKC- $\alpha$, and sh-PKC- $\delta$ cells were incubated for $24 \mathrm{~h}$ with or without ACP $(100 \mu \mathrm{g} / \mathrm{mL})$ or LPS (1 $\mu \mathrm{g} / \mathrm{mL})$. The expression levels of COX-2 were assayed by Western blot. The Western blot results are representative of those obtained in three different experiments. The ELISA data are expressed as the means \pm SD of three separate experiments. *** indicates a significant difference at the level of $p<0.001$ compared to ACP-treated sh-SC cells.

like phenomenon induced by ACP might result from the reduced NF- $\mathrm{kB}$ activation (Figure $6 \mathrm{C}$ ), rather than from the phosphorylation levels of MAPKs (Figure $6 \mathrm{D})$. Based on our results, it is clear that the immunostimulatory activity of ACP is much lower than that of LPS. Induction of LPS tolerance shows the ability of ACP to attenuate high inflammatory responses caused by endotoxins. These results suggested that ACP, without causing severe inflammation, was able to enhance immunity by activating macrophages.

\section{Conclusion}

Over several decades, the complex carbohydrates of mushrooms have attracted growing scientific interest for their immunoenhancing properties. However, their contribution as clinical adjuvants is still limited because of the structural complexity and the lack of studies on the structure-activity relationship and the underlying mechanisms of the biological activity of individual polysaccharide components. The present study reports the immunostimulatory activity of Antrodia cinnamomea galactomannan (ACP) in mouse macrophages and human monocyte derived dendritic cells. We identified TLR4 as the putative receptor for $\mathrm{ACP}$ binding and some signaling pathways involved in ACP-induced macrophage activation to secrete proinflammatory cytokines, TNF-a, and IL-6. Furthermore, the ability of ACP to exert an endotoxin tolerance-like effect on murine macrophages was demonstrated in vitro. We previously explored the detailed structure of ACP and its ability to enhance phagocytosis and bactericidal activity of murine macrophages [29]. In that study, we further reported that ACP pretreatment enhances the immune responses against invading bacteria in the early stage of infection but attenuates the risk of severe inflammation in the latter stages by lowering the secretion of pro-inflammatory cytokines. Considering the above facts and our current data including an endotoxin tolerance-like effect, we suggest ACP as a strong but harmless candidate for the development of new carbohydrate-based nutraceutical supplements and adjuvants in immunotherapy for a broad range of diseases.

\section{Abbreviations}

ACP: Antrodia cinnamomea polysaccharide; TNF-a: tumor necrosis factor-a; IL-6: interleukin-6; IL-1 $\beta$ : interleukin-1 $\beta$; LPS: lipopolysaccharide; MAPKs: mitogen activated protein kinase; PKC: protein kinase C; COX-2: cycloxygenase-2; TLR4: toll-like receptor 4 ; NF-kB: nuclear factor-kB. 
(A)
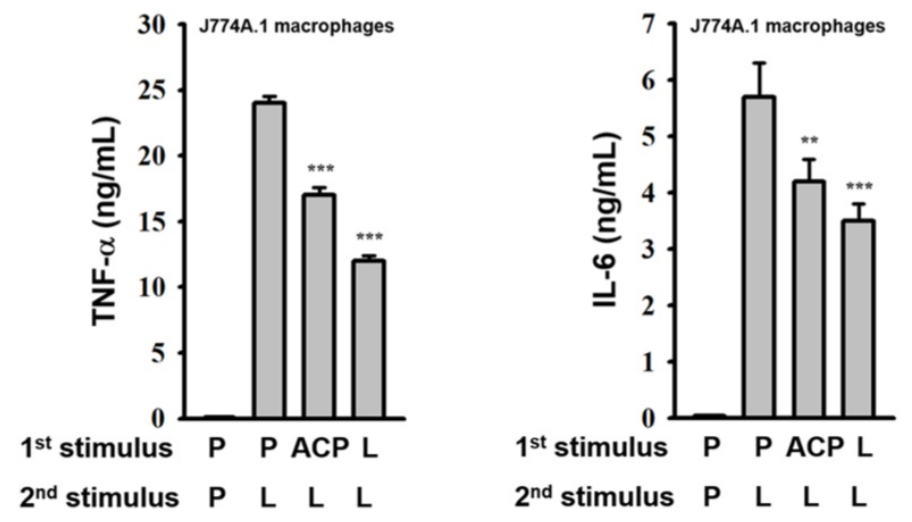

(B)

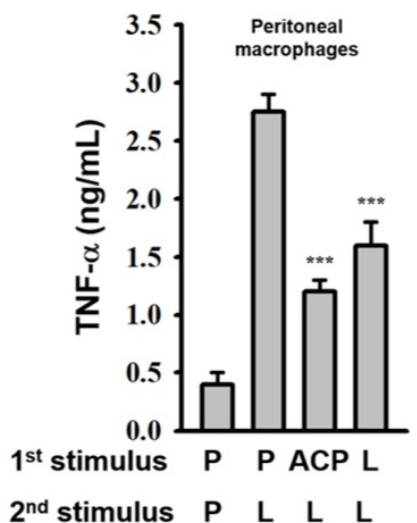

(C)

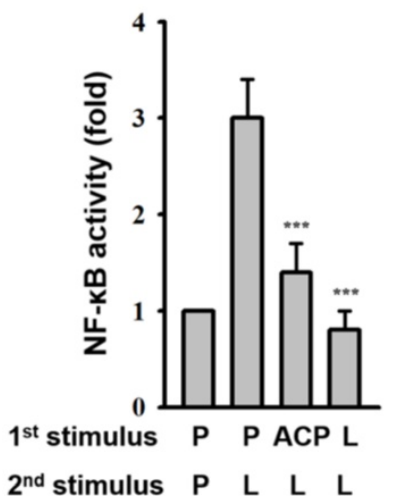

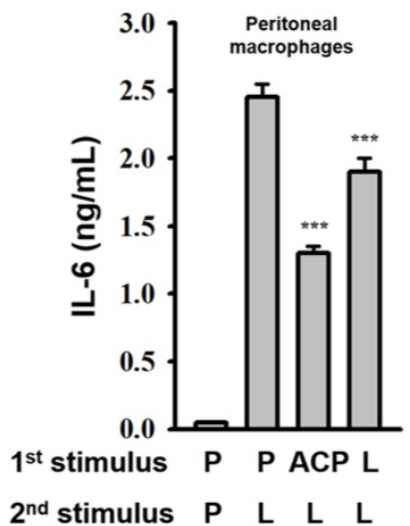

(D)

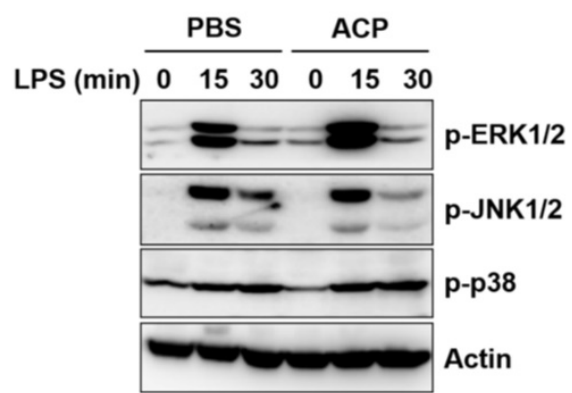

Figure 6. ACP pretreatment induces LPS tolerance. (A, B) J774A.1 macrophages (A) and mouse peritoneal macrophages (B) were incubated for $24 \mathrm{~h}$ with or without ACP $(100 \mu \mathrm{g} / \mathrm{mL})$ or LPS $(0.1 \mu \mathrm{g} / \mathrm{mL})(1$ st stimulus). After washing, cell cultures were changed for fresh medium and then were incubated for $24 \mathrm{~h}$ with or without LPS $(1$ $\mu \mathrm{g} / \mathrm{mL})\left(2^{\text {nd }}\right.$ stimulus). The levels of TNF- $\alpha$ and IL-6 in the culture medium were measured by ELISA. (C) J-Blue cells were incubated for $24 \mathrm{~h}$ with or without ACP (100 $\left.\mu \mathrm{g} / \mathrm{mL}\right)$ or LPS $(0.1 \mu \mathrm{g} / \mathrm{mL})(1$ st stimulus). After washing, cell cultures were changed for fresh medium and then were incubated for $24 \mathrm{~h}$ with or without $\mathrm{LPS}(1 \mu \mathrm{g} / \mathrm{mL})(2$ nd stimulus). The activation levels of NF- $\kappa B$ were measured by an NF- $\kappa B$ reporter assay. (D) J774A.1 macrophages were incubated for $24 \mathrm{~h}$ with or without $A C P$ (100 $\mu \mathrm{g} / \mathrm{mL}$ ). After washing, cell cultures were changed for fresh medium and then were incubated for $0-30$ min with or without LPS $(1 \mu g / \mathrm{mL})$. The phosphorylation levels of ERK $1 / 2$, JNK $1 / 2$ and p38 were assayed by Western blot. The Western blot results are representative of those obtained in three different experiments. The data are expressed as the means \pm SD of three separate experiments. $*^{* *}$ indicates a significant difference at the level of $p<0.001$, compared to 1 st $P / 2^{\text {nd }} L$ group. P: PBS; L: LPS.

\section{Acknowledgments}

Authors gratefully acknowledge the Ministry of Science and Technology (MOST), Taiwan and the
Taiwan International Graduate Program (TIGP), Academia Sinica for providing financial assistance. They also thank Dr. Cindy Lee for language editing and proof reading. 


\section{Competing Interests}

The authors have declared that no competing interest exists.

\section{References}

1. Lu MC, El Shazly M, Wu TY, Du YC, Chang TT, Chen CF, et al. Recent research and development of Antrodia cinnamomea. Pharmacol Ther. 2013; 139: 124-56.

2. Borchers AT, Keen CL, Gershwin ME. Mushrooms, tumors, and immunity: an update. Exp Biol Med (Maywood). 2004; 229: 393-406.

3. Borchers AT, Krishnamurthy A, Keen CL, Meyers FJ, Gershwin ME. The immunobiology of mushrooms. Exp Biol Med (Maywood). 2008; 233: 259-76.

4. Lindequist U, Niedermeyer THJ, Jülich W-D. The pharmacological potential of mushrooms. Evid Based Complement Alternat Med. 2005; 2: 285-99.

5. Lima CU, Cordova CO, Nóbrega OT, Funghetto SS, Karnikowski MG. Does the Agaricus blazei murill mushroom have properties that affect the immune system? An integrative review. J Med Food. 2010; 14: 2-8.

6. Paterson RR, Lima N. Biomedical effects of mushrooms with emphasis on pure compounds. Biomed J. 2014; 37: 357-68.

7. Tsai CC, Yang FL, Huang ZY, Chen CS, Yang YL, Hua KF, et al. Oligosaccharide and peptidoglycan of Ganoderma lucidum activate the immune response in human mononuclear cells. J Agric Food Chem. 2012; 60: 2830-7.

8. Kim GY, Lee MY, Lee HJ, Moon DO, Lee CM, Jin CY, et al. Effect of water-soluble proteoglycan isolated from Agaricus blazei on the maturation of murine bone marrow-derived dendritic cells. Int Immunopharmacol. 2005; 5: 1523-32.

9. Hetland G, Johnson E, Lyberg T, Bernardshaw S, Tryggestad AM, Grinde B. Effects of the medicinal mushroom Agaricus blazei Murill on immunity, infection and cancer. Scand J Immunol. 2008; 68: 363-70.

10. Katoh R, Ooshiro M. Enhancement of antitumor effect of tegafur/uracil (UFT) plus leucovorin by combined treatment with protein-bound polysaccharide, PSK, in mouse models. Cell Mol Immunol. 2007; 4: 295-9.

11. $\mathrm{Xu} \mathrm{Z}$, Chen X, Zhong Z, Chen L, Wang Y. Ganoderma lucidum polysaccharides: immunomodulation and potential anti-tumor activities. Am J Chin Med. 2011; 39: 15-27.

12. Mohammed A, Adelaiye AB, Abubakar MS, Abdurahman EM. Effects of aqueous extract of Ganoderma lucidum on blood glucose levels of normoglycemic and alloxan-induced diabetic wistar rats. J Med Plants Res. 2007; 1: 34- 7.

13. Chang CJ, Lin CS, Lu CC, Martel J, Ko YF, Ojcius DM, et al. Corrigendum: Ganoderma lucidum reduces obesity in mice by modulating the composition of the gut microbiota. Nat Commun. 2017; 8: 16130

14. Wasser S. Medicinal mushrooms as a source of antitumor and immunomodulating polysaccharides. Appl Microbiol Biotechnol. 2002; 60: 258-74.

15. Ngai PHK, Ng TB. Lentin, a novel and potent antifungal protein from shitake mushroom with inhibitory effects on activity of human immunodeficiency virus-1 reverse transcriptase and proliferation of leukemia cells. Life Sci. 2003; 73: 3363-74.

16. Wang HC, Chu FH, Chien SC, Liao JW, Hsieh HW, Li WH, et al. Establishment of the metabolite profile for an Antrodia cinnamomea health food product and investigation of its chemoprevention activity. J Agric Food Chem. 2013; 61: 8556-64.

17. Geethangili M, Tzeng YM. Review of pharmacological effects of Antrodia camphorata and its bioactive compounds. Evid Based Complement Alternat Med. 2011; 2011: 17

18. Hsiao G, Shen MY, Lin KH, Lan MH, Wu LY, Chou DS, et al. Antioxidative and hepatoprotective effects of Antrodia camphorata extract. J Agric Food Chem. 2003; 51: 3302-8.

19. Chen X, Hu ZP, Yang XX, Huang M, Gao Y, Tang W, et al. Monitoring of immune responses to a herbal immuno-modulator in patients with advanced colorectal cancer. Int Immunopharmacol. 2006; 6: 499-508.

20. Chen JJ, Lin WJ, Liao CH, Shieh PC. Anti-inflammatory benzenoids from Antrodia camphorata. J Nat Prod. 2007; 70: 989-92.

21. Chen CC, Liu YW, Ker YB, Wu YY, Lai EY, Chyau CC, et al. Chemical characterization and anti-inflammatory effect ofpolysaccharides fractionated from submerge-cultured Antrodia camphorata mycelia. J Agric Food Chem. 2007; 55: 5007-12.

22. Chiu $\mathrm{CH}$, Peng $\mathrm{CC}$, Ker YB, Chen $\mathrm{CC}$, Lee A, Chang WL, et al. Physicochemical characteristics and anti-inflammatory activities of antrodan, a novel glycoprotein isolated from Antrodia cinnamomea mycelia. Molecules (Basel, Switzerland). 2013; 19: 22-40.
23. Lin CC, Pan IH, Li YR, Pan YG, Lin MK, Lu YH, et al. The adjuvant effects of high-molecule-weight polysaccharides purified from Antrodia cinnamomea on dendritic cell function and DNA vaccines. PLoS One. 2015; 10: e0116191.

24. Liu JJ, Huang TS, Hsu ML, Chen CC, Lin WS, Lu FJ, et al. Antitumor effects of the partially purified polysaccharides from Antrodia camphorata and the mechanism of its action. Toxicol Appl Pharmacol. 2004; 201: 186-93.

25. Fa KN, Yang CM, Chen PC, Lee YY, Chyau CC, Hu ML. Anti-metastatic effects of antrodan, the Antrodia cinnamomea mycelia glycoprotein, in lung carcinoma cells. Int J Biol Macromol. 2015; 74: 476-82.

26. Tsai M-C, Song TY, Shih PH, Yen GC. Antioxidant properties of water-soluble polysaccharides from Antrodia cinnamomea in submerged culture. Food Chem. 2007; 104: 1115-22.

27. Cheng JJ, Lu MK, Lin CY, Chang CC. Characterization and functional elucidation of a fucosylated 1,6-a-D-mannogalactan polysaccharide from Antrodia cinnamomea. Carbohydr Polym. 2011; 83: 545-53.

28. Liu Y, Ding Y, Ye M, Zhu T, Tian D, Ding K. A novel heterogalactan from Antrodia camphorata and anti-angiogenic activity of its sulfated derivative. Polymers. 2017; 9: 228.

29. Perera N, Yang FL, Chang CM, Lu Y-T, Zhan SH, Tsai Y-T, et al. Galactomannan from Antrodia cinnamomea enhances the phagocytic activity of macrophages. Org Lett. 2017; 19: 3486-9.

30. Isaacs D. Infectious risks associated with biologics. Adv Exp Med Biol. 2013; 764: 151-8.

31. Arango DG, Descoteaux A. Macrophage cytokines: involvement in immunity and infectious diseases. Front Immunol. 2014; 5: 491.

32. Dinarello CA. Proinflammatory cytokines. Chest. 2000; 118: 503-8.

33. Scheller J, Chalaris A, Schmidt Arras D, Rose-John S. The pro- and anti-inflammatory properties of the cytokine interleukin-6. Biochim Biophys Acta. 2011; 1813: 878-88.

34. Li CY, Chao LK, Wang SC, Chang HZ, Tsai ML, Fang SH, et al. Honokiol inhibits LPS-induced maturation and inflammatory response of human monocyte-derived dendritic cells. J Cell Physiol. 2011; 226: 2338-49.

35. Lee IH, Huang RL, Chen CT, Chen HC, Hsu WC, Lu MK. Antrodia camphorata polysaccharides exhibit anti-hepatitis B virus effects. FEMS Microbiol Lett. 2002; 209: 63-7.

36. Chang JS, Kuo HP, Chang KL, Kong ZL. Apoptosis of hepatocellular carcinoma cells induced by nanoencapsulated polysaccharides extracted from Antrodia camphorata. PLoS One. 2015; 10: e0136782.

37. Meng LM, Pai MH, Liu JJ, Yeh SL. Polysaccharides from extracts of Antrodia camphorata mycelia and fruiting bodies modulate inflammatory mediator expression in mice with polymicrobial sepsis. Nutrition (Burbank, Los Angeles County, Calif). 2012; 28: 942-9.

38. Cheng JJ, Huang NK, Chang TT, Wang DL, Lu MK. Study for anti-angiogenic activities of polysaccharides isolated from Antrodia cinnamomea in endothelial cells. Life Sci. 2005; 76: 3029-42.

39. Yang CM, Zhou YJ, Wang RJ, Hu ML. Anti-angiogenic effects and mechanisms of polysaccharides from Antrodia cinnamomea with different molecular weights. J Ethnopharmacol. 2009; 123: 407-12.

40. Chen YJ, Cheng PC, Lin CN, Liao HF, Chen YY, Chen CC, et al Polysaccharides from Antrodia camphorata mycelia extracts possess immunomodulatory activity and inhibits infection of Schistosoma mansoni. Int Immunopharmacol. 2008; 8: 458-67.

41. Ker YB, Peng CH, Chang Wi, Chyau CH, Peng RY. Hepatoprotective bioactivity of the glycoprotein, Antrodan, Isolated from Antrodia cinnamomea mycelia. PLoS One. 2014; 9: e93191.

42. Hsu HY, Hua KF, Lin CC, Lin CH, Hsu J, Wong CH. Extract of Reishi polysaccharides induces cytokine expression via TLR4-modulated protein kinase signaling pathways. J Immunol. 2004; 173: 5989-99.

43. Liu JY, Yang FL, Lu CP, Yang YL, Wen CL, Hua KF, et al. Polysaccharides from Dioscorea batatas induce tumor necrosis factor-alpha secretion via Toll-like receptor 4-mediated protein kinase signaling pathways. J Agric Food Chem. 2008; 56: 9892-8.

44. Hsu HY, Jeyashoke $\mathrm{N}$, Yeh $\mathrm{CH}$, Song YJ, Hua KF, Chao LK. Immunostimulatory bioactivity of algal polysaccharides from Chlorella pyrenoidosa activates macrophages via Toll-like receptor 4. J Agric Food Chem. 2010; 58: 927-36

45. Yang FL, Yang YL, Liao PC, Chou JC, Tsai KC, Yang AS, et al. Structure and immunological characterization of the capsular polysaccharide of a pyrogenic liver abscess caused by Klebsiella pneumoniae: activation of macrophages through Toll-like receptor 4. J Biol Chem. 2011; 286: 21041-51.

46. Lin $\mathrm{MH}$, Yang $\mathrm{YL}$, Chen $\mathrm{YP}$, Hua KF, Lu CP, Sheu F, et al. A novel exopolysaccharide from the biofilm of Thermus aquaticus YT-1 induces the immune response through Toll-like receptor 2. J Biol Chem. 2011; 286: $17736-45$.

47. Takeda K, Akira S. Toll-like receptors. Curr Protoc Immunol. 2015; 109: 14.2.1-0. 
48. Hsu TL, Cheng SC, Yang WB, et al. Profiling carbohydrate-receptor interaction with recombinant innate immunity receptor-Fc fusion proteins. J Biol Chem. 2009; 284: 34479-34489.

49. Masuoka J. Surface glycans of Candida albicans and other pathogenic fungi: physiological roles, clinical uses, and experimental challenges. Clin Microbiol Rev. 2004; 17: 281-310.

50. Zhang X, Qi C, Guo Y, Zhou W, Zhang Y. Toll-like receptor 4-related immunostimulatory polysaccharides: Primary structure, activity relationships, and possible interaction models. Carbohydr Polym. 2016; 149: 186-206.

51. Cario E, Gerken G, Podolsky DK. Toll-like receptor 2 enhances ZO-1-associated intestinal epithelial barrier integrity via protein kinase C. Gastroenterology. 2004; 127: 224-38.

52. Fan H, Cook JA. Molecular mechanisms of endotoxin tolerance. J Endotoxin Res. 2004; 10: 71-84.

53. Wheeler DS, Lahni PM, Denenberg AG, Poynter SE, Wong HR, Cook JA, et al. Induction of endotoxin tolerance enhances bacterial clearance and survival in murine polymicrobial sepsis. Shock (Augusta, Ga). 2008; 30: 267-73. 